Artículo de investigación

Apuntes del CENES

ISSN 0120-3053

Volumen $34-\mathrm{N}^{\circ} .59$

enero - junio de 2015

Págs. 39-62

\title{
Hacia una noción sobre la pobreza
}

\author{
Towards a concept on poverty
}

Rumo a um conceito sobre pobreza

\author{
Julián Augusto Casas Herrera* \\ Rodrigo Barichello ${ }^{* *}$
}

Fecha de recepción: 29 de julio de 2014

Concepto de evaluación: 1 de octubre de 2014

Fecha de aprobación: 28 de noviembre de 2014

* Economista. Especialista en finanzas de la Universidad Pedagógica y Tecnológica de Colombia (UPTC) y Magister en Ciencias Económicas de la Universidad Nacional de Colombia (Sede Bogotá). Docente de la Escuela de Economía de la UPTC. Tunja, Colombia. Dirección de correspondencia: calle 33 A \# 17 A 59. Tunja. Colombia. Correo electrónico: julian.casas01@uptc.edu.co

** Administrador de Empresas. Magister en ingeniería de producción y candidato a doctor en ingeniería de producción de la Universidad Federal de Santa Catarina (UFSC) de Brasil. Docente de la universidad comunitaria de la región de chapecó (UNOCHAPECO) de Brasil. Dirección decorrespondencia: Rua Menna Barreto 210 E-Apartamento 1001-1, Bairro São Cristovão. Chapecó/SC CEP 89803-280 Brasil. Correo electrónico: rodrigo.b@unochapeco.edu.br Los autores agradecen los comentarios que hicieron los profesores Manuel Muñoz y Guillermo Rivas, quienes son autoridad y punto de referencia a la hora de hablar sobre la teorización de la pobreza en Colombia. 


\title{
Resumen
}

Este artículo analiza los antecedentes relacionados con la pobreza y hace una síntesis de los principales elementos del fenómeno que permiten abordar el estudio del mismo. Con este fin, se sitúa temporalmente el comienzo de la pobreza en el mundo, lo que conduce, por una parte, a distinguir entre pobreza y desigualdad y, por otra, a observar la forma como se ha intentado plantear el análisis del fenómeno de la pobreza, que aún sigue teniendo vigencia, puesto que el $40 \%$ de la población mundial la sufre.

Palabras clave: pobreza, componentes, métodos de medición.

JEL: D31, D60, E20, H75, I31, I32

\begin{abstract}
This paper analyzes the background associated with poverty and makes a synthesis of the main elements of the phenomenon that allow addressing its study. To accomplish this, the start of the poverty in the world is located temporarily, which leads, on the one hand, to distinguish between poverty and inequality and, on the other, to observe how has been tried to approach the analysis of the phenomenon of poverty, that still remains valid, since $40 \%$ of the world population suffers it.
\end{abstract}

Keywords: poverty, components, measuring methods.

\section{Resumo}

Este artigo analisa os antecedentes associados à pobreza e apresenta uma síntese dos principais elementos do fenômeno que permitem abordar o estudo do mesmo. Para o alcance dos objetivos, se situa temporalmente o início da pobreza no mundo, o que conduz, por um lado, a distinguir pobreza e desigualdade, e por outro lado, observar a forma como tem-se tentado abordar o estudo e a análise do fenômeno da pobreza, que ainda permanece válida, uma vez que $40 \%$ da população mundial sofre com o mesmo.

Palavras chaves: pobreza, componentes, métodos de medição. 


\section{INTRODUCCIÓN}

Este documento se justifica como elemento clarificador de los principales aspectos en el análisis de la pobreza. Tiene cuatro secciones, la primera es la introducción, la segunda muestra los orígenes de la pobreza y distingue entre pobreza y desigualdad, la tercera hace una aproximación al concepto de pobreza, a partir de la exposición de cinco componentes, centrando particularmente la atención sobre la medición de la pobreza. Finalmente, se concluye mostrando la relevancia y vigencia del análisis de la pobreza, puesto que el $40 \%$ de la población mundial sufre de este flagelo $y$, por ende, se precisa una mejor comprensión del fenómeno para que se establezcan políticas públicas acertadas que favorezcan efectivamente a los más afectados por la pobreza.

\section{ORÍGENES DE LA POBREZA}

Etimológicamente, la palabra "pobreza" procede del sustantivo pobre, que viene del latín pauper-pauperis ${ }^{1}$, cuyo significado es infértil. Se esperaría que riqueza, que proviene de rico, expresara fertilidad. Sin embargo, esta palabra desciende del gótico riks que significa poderoso. No obstante, el posible significado de la palabra pobre está relacionado con poca o nula producción, mientras que rico, además de relacionarse con el poder, también tiene que ver con el acceso mayoritario a bienes y servicios.

Por otra parte, el Diccionario de la Real Academia Española define pobreza como falta y escasez. A su vez, define escasez como pobreza o falta de lo necesario para subsistir (RAE, s.f.). Así, la definición tiene un carácter tautológico y

$\overline{1}$ Proviene de paucus (poco) y pariré (engendrar), (dechile.net, s.f.). 
circular. A pesar de ello, se puede afirmar que la mayoría de autores, sin importar su línea de pensamiento, concuerdan en señalar que la pobreza es carencia o insuficiencia de un atributo con relación a un umbral. Por ejemplo, insuficiencia de ingresos con relación a una línea de pobreza (LP), insuficiencia de años de educación frente a la media del país, entre otros. Por tanto, si las personas se sitúan por debajo del umbral fijado serán consideradas pobres respecto del atributo elegido ${ }^{2}$ (Coudouel, Hentschel \& Wodon, 2002).

$\mathrm{Al}$ rastrear los orígenes de la pobreza se encuentra que en el Corán se menciona 26 veces la palabra pobres y cuatro veces la palabra pobreza. Igualmente, la Biblia nombra 76 veces la palabra pobres y en 18 ocasiones la palabra pobreza. Nótese que incluso en libros tan antiguos aparece el fenómeno de la pobreza, pero desde cuándo apareció en el planeta:

... hace 20.000 años, los humanos inventaron la agricultura. Hasta entonces éramos cazadores y recolectores, y casi todos los estudios apuntan a que este tipo de sociedades eran (...) igualitarias. Pero cuando inventamos la agricultura, inventamos los excedentes, apareció la gente que quería controlar esos excedentes y, así surgió la jerarquía y (...) la pobreza (Punset, 2005, p. 100).
De la cita se desprenden dos elementos: la problemática ligada a la distribución del excedente y la relación entre pobreza y desigualdad. El primer elemento fue analizado por los autores del pensamiento económico clásico. Estos teorizaron sobre el problema del valor y la distribución. De hecho, los principales temas de análisis que los ocuparon están relacionados con la determinación de las causas del incremento de la riqueza, lo mismo que de las leyes que regulan su distribución entre las diferentes clases de la sociedad. Así, para los clásicos era indispensable valorar los bienes porque permitiría saber cuánto había para distribuir entre los miembros de la sociedad (Cuevas, 1993).

Sin embargo, es necesario reflexionar hasta qué punto el fenómeno de la pobreza está relacionado con los problemas de la distribución de ingresos, recursos productivos, tierra, capital, entre otros. Pardo (2000) señala que para Adam Smith y David Ricardo, la pobreza está relacionada con asuntos distributivos e institucionales de las economías capitalistas. Para Smith, la inequidad es la principal causa de la pobreza. No obstante, la justificaba para garantizar la estabilidad del orden social capitalista; en cambio, para Ricardo, la pobreza depende de las dinámicas del conflicto distributivo y del crecimiento poblacional.

Smith entrevé la relación entre pobreza y desigualdad, a partir de la aparición de la

$\overline{2} \quad$ Nótese que el atributo o parámetro por evaluar puede ser monetario o no monetario. 
propiedad privada. De hecho, Smith sostiene que el objeto del gobierno es proteger la riqueza y defender al rico del pobre. Así, para Smith, son necesarias las distinciones entre los ricos y los pobres, convirtiendo la inequidad como el resultado de un convenio social entre propietarios privados y líderes políticos, en el que estos últimos legitiman los intereses de los primeros (Pardo, 2000). Asimismo, Smith (1997) afirma que los pobres son solo quienes pueden sostenerse por su trabajo. De hecho, señala que:

Los patronos no pueden situar los salarios por bajo cierta tasa, a saber: la subsistencia del trabajador, más una cierta cantidad para el sustento de su familia (...) Existe, sin embargo, una conexión entre el precio de la mano de obra y el de las provisiones (Smith, 1997, p. 66-83) $)^{3}$.

Por otra parte, Ricardo señala que la pobreza afecta a las clases trabajadoras y reduce el bienestar de la sociedad. De ahí que el trabajo y los salarios son fundamentales para entender las razones sobre las cuales persiste la pobreza. De hecho, da tres causas de su persistencia: i) la relación dinámica entre las fuerzas demográficas y económicas no favorecen a los pobres; ii) el proceso de acumulación perpetúa la inequidad; y iii) las razones institucionales defienden los intereses de los ricos ${ }^{4}$.

En último término, Pardo (2000) señala que tanto Smith como Ricardo aceptan tres premisas: i) la inequidad continuará, pero la tendencia de la sociedad hacia el progreso económico y social, a través de la acumulación de capital, mitigaría la pobreza; ii) la libertad es fundamental para reducir la pobreza; y iii) el Estado solo debe intervenir para mejorar el nivel de educación de los pobres.

En cuanto al segundo elemento - la relación entre pobreza y desigualdad- (Sen, $1992)^{5}$, se puede decir, en principio, que si hubiera igualdad no habría pobreza. No obstante, la relación es más compleja, ya que cuando se aborda el problema de la igualdad se debe precisar, como lo hace notar Sen (1979), igualdad de qué. En ese sentido, este documento centra su atención en la variable ingreso, ya que la pobreza, desde el principio, se ha relacionado con esta (Townsend, 2007). Por tanto, el ingreso se sitúa en el centro de la discusión, junto con la forma como se distribuye entre los individuos de una sociedad.

Fundamentalmente, la distinción conceptual entre desigualdad y pobreza pasa por el hecho de que esta última es una

3 El postulado de Smith tiene relación con el método de la LP absoluta. Concretamente con la canasta básica o línea de indigencia, que se puede revisar en la segunda parte del artículo, en el componente de la medición.

4 Ricardo creía que la pobreza había vuelto perezosa a la gente. Por eso, fue enemigo de los subsidios, ya que consideró que el proceso de acumulación y el libre mercado ajustarían el crecimiento poblacional, así como la mejoría de la población pobre.

5 Señala que analizar la pobreza como un problema de desigualdad o viceversa, no le haría justicia a ninguno de los dos conceptos. Ambos conceptos están relacionados, pero ninguno de los dos sustituye al otro. 
medida absoluta de bienestar, mientras que la primera es una medida relativa del bienestar. Es decir, la desigualdad es un concepto más amplio porque abarca la totalidad de la población, junto con la distribución del ingreso entre los miembros de la misma. En cambio, la pobreza solo centra su atención en los que se encuentran situados por debajo del umbral que establece una LP; estos son los que están en la parte inferior de la distribución del ingreso. En otras palabras, una manera de diferenciar entre desigualdad y pobreza, es que la primera compara la situación de un hogar con la de otros; mientras que la segunda surge al cotejar la situación del hogar con una norma o conjunto de normas, que se refleja en el umbral definido (Boltvinik, 1999).

En este sentido, se supone que la relación se ubica en la cuantía de ingresos que posee un individuo frente a los otros; por tanto, se podría decir, por ejemplo, que si hay una sociedad con dos individuos y uno de ellos posee el $90 \%$ del ingreso total de la sociedad, y el otro el resto, se tendrían los siguientes elementos: i) acerca de la igualdad se expresará que hay un alto grado de concentración del ingreso, pues el $50 \%$ de la sociedad concentra el $90 \%$ de ingreso; ii) refe- rente a la pobreza, habrá que tener en cuenta el umbral definido en la sociedad para determinar si el individuo con el $10 \%$ del ingreso está o no en situación de pobreza. Así, si el umbral de la LP se sitúa por debajo del $10 \%$, se dirá que ese individuo está en una sociedad desigual, pero no es pobre. Por ende, pobreza no es sinónimo de desigualdad.

De lo anterior, se desprenden juicios de valor, tales como: eso es injusto, es una situación inaceptable, entre otros. Al ubicar la discusión en estos términos ya no se está hablando de igualdad, sino de inequidad. Es decir, la manera como debería distribuirse el ingreso entre los individuos de la sociedad ${ }^{6}$. Sin embargo, el alcance del documento no cobija las temáticas relacionadas con la desigualdad e inequidad, puesto que la complejidad de cada una amerita análisis detallados: solo se encarga de abordar la pobreza. En ese sentido, una de las primeras miradas sociales sobre la pobreza surgió:

hacia finales de la Alta Edad Media (...) en 1601, [con] la promulgación de las Leyes de Pobres, en Inglaterra bajo el reinado de Isabel I. A partir de allí (...) esta mirada fue modificada y amplificada por

\footnotetext{
Una confusión en la que se suele caer es pensar que igualdad es sinónimo de equidad, así como desigualdad e inequidad. Un ejemplo podría aclarar ambos conceptos. Suponga una sociedad con dos personas: A gana \$1000 y B gana $\$ 5000$. Se dirá que en esa sociedad hay igualdad cuando ambas pagan $\$ 100$ de impuestos, puesto que las dos pagarán exactamente el mismo valor. Sin embargo, en esa sociedad no hay equidad, si se considera que dado que B gana más debería pagar más. En síntesis, hay equidad cuando se incluyen criterios normativos para que la tributación se distribuya de manera más "justa" entre los miembros de la sociedad; y hay igualdad si todos pagan por igual. Asimismo, Corrado Gini (creador del coeficiente de Gini) en una entrevista contestó a la pregunta: "¿Por qué es un error utilizar desigualdad e inequidad como sinónimos?”, lo siguiente: "Porque se refieren a planos distintos. Igualdad y desigualdad son conceptos estadísticos; equidad e inequidad son conceptos éticos o morales. Los primeros sirven para describir una realidad, los segundos para calificarla" (De Pablo, 2012).
} 
las acciones del Estado moderno posterior a la Revolución Francesa (Consiglio, 2007, p. 10).

En el mismo sentido, Townsend (2007) señala que en:

Inglaterra, antes de la época de Isabel I (...) se promulgaron diversas leyes para regular y mantener a los pobres, y el primer grupo registrado de "Comisionados para los Pobres" comenzó a trabajar en $1630(\ldots) \mathrm{Al}$ final del siglo XVIII, los gobiernos y los grupos dominantes se sintieron obligados de mala gana a definir las necesidades de los pobres en relación con su ingreso. En Gran Bretaña y gran parte de Europa, aquellos encargados de áreas pequeñas tales como parroquias, desarrollaron formas internas y externas de alivio de la pobreza mucho antes de la revolución industrial. Las economías recientemente basadas en las industrias manufactureras y en un sistema de salario trajeron nuevos problemas relacionados con el cálculo y la regulación de las sumas que debían recibir los pobres dentro y fuera de las instituciones para los pobres. El principio de "menos aceptable" jugó un rol crucial en el pensamiento tanto de los políticos como de aquellos encargados de las investigaciones científicas (Townsend, 2007, p. 15).

Townsend (2007) manifiesta que la historia de la pobreza ha pasado por distin- tas etapas: entrega de pan, beneficios en especies, efectivo e incluso una combinación de efectivo y pan. No obstante, en estas entregas había un elemento concluyente: determinar quién debia ser el merecedor de estos beneficios. Para acordar esto los gobiernos empezaron definiendo las necesidades mínimas nutricionales de los pobres. Lo anterior llevó a nutricionistas alemanes, británicos y estadounidenses a adelantar investigaciones sobre los requerimientos nutricionales necesarios para mantener vivos a los individuos.

De este modo, la pobreza desde el principio se relacionó con el ingreso. Pero su construcción es problemática, porque precisa aclarar dos elementos para medir la pobreza: ingreso y privación. La medición del primero debe incluir el valor de los bienes e ingreso en especies que puedan ser tratados como equivalentes al ingreso. En cambio, la medición de la privación necesita decidir los elementos esenciales que deban incluirse de la actividad humana de determinada sociedad.

A raíz de lo anterior, Townsend (2007) señala que desde 1880, a la fecha, se han desarrollado particularmente tres concepciones de la pobreza: subsistencia, necesidades básicas y privación relativa. Desde la primera concepción, son pobres, según Rowntree (1901), aquellas personas cuyos ingresos no son "suficientes para obtener lo mínimo necesario para mantener tan sólo la eficiencia física". Luego se consideró que dicha concepción era muy reducida y, por ello, 
se amplió para establecer que una familia estaría en situación de pobreza si su ingreso menos el arriendo estaba por debajo de una LP determinada. Cabe indicar que en el cálculo del ingreso se contemplaba una asignación para vestuario, combustible y otros ítems. No obstante, la mayor porción del ingreso se destinaba a la alimentación. Así, los aportes de Rowntree influenciaron las prácticas científicas y las políticas internacionales y nacionales para el resto del siglo XX.

Sin embargo, la concepción de subsistencia se criticó porque consideraba únicamente las necesidades humanas como necesidades físicas (alimento, techo y abrigo) y no contemplaba necesidades sociales. Por ello, desde 1970 el concepto de necesidades básicas ganó fuerza por incluir dos elementos:

i) ciertos requerimientos mínimos de una familia para consumo privado: alimentación adecuada, techo y abrigo, como también ciertos muebles y equipamiento doméstico;

ii) servicios esenciales proporcionados por y para la comunidad sin restricciones, tales como agua potable confiable, medidas sanitarias, transporte público y salud, educación e infraestructura cultural (Townsend, 2007, p. 18).

No obstante, la concepción de necesidades también tuvo reparos debido a que las necesidades nacionales no son las mismas comparadas frente a las de otros países del mundo. Por ello, desde las dos últimas décadas del siglo XX surgió la concepción de privación relativa, que relativiza los recursos a las condiciones sociales y materiales de cada momento histórico de la sociedad, ya que la:

gente que vive en el presente no está sujeta a las mismas leyes y obligaciones, ni a las costumbres que prevalecían en épocas anteriores (...) $[$ Por tanto, existen] importantes objeciones a la simple actualización de cualquier parámetro histórico de la pobreza sobre la base de algún índice de precios (Townsend, 2007, p. 20).

Por lo anterior, se deduce que la pobreza, por su naturaleza dinámica y cambiante, en tiempo y en espacio, se ha modificado con el paso de las diferentes épocas, debido a que es un fenómeno social polifacético. Por ello, exige que en cada momento de la historia se le analice de un modo específico desde sus distintos componentes. Estos se comentan en la siguiente sección.

\section{COMPONENTES DE LA POBREZA}

La pobreza es un fenómeno antiguo, que se refleja en la carencia o insuficiencia de un atributo respecto de un umbral preestablecido. Sin embargo, la pobreza incomoda y duele. Por ello su análisis ha sido abordado por parte de historiadores, sociólogos y economistas, desde cinco componentes que se explicitan a continuación. 


\section{Enfoques}

Partiendo del reconocimiento de que la pobreza existe en la vida de los seres humanos, es necesario dirigir la atención a esta desde una perspectiva peculiar, con el fin de observarla, reconocerla y caracterizar sus principales rasgos, para comprender su dinámica y así asumir una perspectiva al abordarla, e igualmente diferenciar quién podría caer en condición de pobreza basado en unas necesidades que deberían ser satisfechas. No obstante, cada enfoque varía en su perspectiva de lo que considera adecuado para diferenciar quién podría caer en condición de pobreza.

En ese orden de ideas, Marx (1967) manifestó que las necesidades de los individuos son las mismas en las distintas sociedades, lo que varía son los modos de cubrirlas, ya que dependen de las costumbres de las mismas. De lo anterior surgieron los enfoques relativo y absoluto. El relativo, según Feres y Mancero (2000), plantea que la condición de pobreza surge a partir de la comparación entre individuos, es decir, depende del nivel general de riqueza existente en la sociedad. De este modo, si las personas no alcanzan un nivel medio estándar de vida acorde con la sociedad en la que viven, se hallarán en condición de pobreza.
El enfoque absoluto ${ }^{7}$, de acuerdo con Feres y Mancero (2000, p. 11): "sostiene que las necesidades (...) [son independientes] de la riqueza de los demás, y no satisfacerlas revela una condición de pobreza en cualquier contexto". Por ende, si los individuos no satisfacen las necesidades más básicas se encontrarán en condición de pobreza. Sin embargo, para Sen (1992), el enfoque relativo complementa, pero no reemplaza el análisis de pobreza en términos del absoluto ${ }^{8}$.

Además de los enfoques señalados, que son los más utilizados en el mundo, autores como Sen (1997), Rawls (1982), Boltvinik (2007a), Kapteyn, Kooreman y Willemse (1988) han propuesto distintos enfoques para abordar el análisis de la pobreza. Sen (1997) planteó el enfoque de capacidades, en el que los bienes no son los que determinan el estándar de vida, porque la posesión de estos no indica las actividades que un individuo puede realizar, ya que dependen de las facultades e impedimentos que tenga cada uno. Por ello, la facultad de realizar acciones es lo que determina el nivel de vida, y no la posesión de objetos.

En el análisis que hace Sen, también, se distingue entre funcionamientos ${ }^{9}$, capa- $^{-}$

\footnotetext{
Este enfoque supone que cada persona u hogar tiene la misma función de utilidad y que los individuos son maximizadores de utilidad. El ingreso personal o del hogar sirve como indicador de bienestar.

8 Ha habido una controversia entre los enfoques absoluto y relativo, que pasa por advertir que el umbral o LP tiene dos componentes: un núcleo absoluto universal y uno relativo específico para cada sociedad. Así, el absoluto se refiere estrictamente a la subsistencia; mientras que el enfoque relativo señala que los hogares o individuos son más que alimentos, razón por la cual se deben ajustar otras necesidades esenciales para cada sociedad (Boltvinik, 1999).

9 Conocidos como functionings, que según Vargas $(2004$, p. 6) "representan partes del estado de una persona: en particular, las cosas que logra hacer o ser al vivir, es decir "las diversas condiciones de vida (las diversas dimensiones de ser y el hacer) que pueden o no ser alcanzadas".
} 
cidades ${ }^{10}$ y bienes y servicios. Así, mientras que el funcionamiento es un logro, la capacidad es la habilidad para obtener ese logro (Vargas, 2004). Entonces, cualquier bien o servicio debe ser valorado no en sí mismo sino por las capacidades que le permite desarrollar al individuo para alcanzar los funcionamientos. Por ello, cuando Sen habla de pobreza, se refiere a aquella situación, en la que el individuo es incapaz de alcanzar los funcionamientos más básicos, cruciales e importantes para la vida del mismo.

El enfoque igualitario de Rawls (1982) le da un lugar prioritario a la libertad y a la igualdad. Asimismo, propone los bienes primarios, es decir, aquellos que todo hombre racional quiere tener. Dichos bienes son: libertades básicas, libertad de movimiento, libertad de elección de ocupación en medio de distintas oportunidades, propender a las bases sociales del respeto a uno mismo, posibilidades de asumir cargos con responsabilidad en instituciones políticas y económicas, libertad para poseer renta y alcanzar la riqueza. Para este enfoque, la pobreza se manifiesta en aquellas personas que tienen menos bienes primarios, lo que las convierte en las personas más vulnerables de la sociedad (Rawls, 1982). Por tanto, las personas que vean restringida su libertad e igualdad para alcanzar los bienes primarios, estarán sumidas en la pobreza.
Por otra parte, Boltvinik (2007a) propuso el enfoque del florecimiento humano, que sugiere un cambio radical en las instituciones políticas y económicas internacionales debido a que tienen una concepción muy limitada de las necesidades humanas y de la pobreza. Para este enfoque, la condición de pobreza aparece en la existencia del ser humano cuando este es vulnerado por la sociedad, particularmente, cuando las condiciones de producción y las relaciones sociales lo excluyen y se muestran indiferentes ante su situación, lo cual conlleva el reforzamiento de su estado de pobreza. Desde tal perspectiva, la mayoría de personas no cuentan con tiempo libre para recrear la transformación del orden social, es decir, renuncian a la utopía y, por ende, a la posibilidad de vivir en un mundo mejor. En este ámbito no es posible el florecimiento humano.

Finalmente, De Vos y Garner (1991), Kapteyn, Kooreman y Willemse (1988), Pradhan y Ravallion (1998), entre otros autores, han planteado en los últimos años un análisis de la pobreza desde la perspectiva subjetiva de las personas. A este se le denomina enfoque subjetivo, que intenta capturar la percepción que tienen los pobres sobre su situación. Es decir, se busca no solo enfocar la perspectiva en la variable renta/consumo ${ }^{11}$ de los hogares o personas, sino también la manera que tienen estas para valorar

\footnotetext{
Se suelen encontrar como capabilities. Estas se refieren a las habilidades que tiene una persona para alcanzar ciertas condiciones de vida. Vargas $(2004$, p. 6) indica que "la capacidad de una persona refleja combinaciones alternativas de los funcionamientos que esta puede lograr". Por ello, la calidad de vida debe evaluarse en términos de la capacidad para lograr funcionamientos.

11 En ocasiones no se dice renta sino ingreso, y en lugar de consumo se dice gasto.
} 
su condición de vida. No obstante, el grado de utilización del enfoque subjetivo ha sido exiguo.

\section{Definiciones}

A raíz de los enfoques aparecen las incontables definiciones de la pobreza, que intentan caracterizar los principales rasgos genéricos y diferenciales de la misma desde la perspectiva de cada autor. Las definiciones pueden agruparse en dos categorías: unidimensionales y multidimensionales. Las primeras se caracterizan por relacionar la pobreza con una situación de insuficiencia o carencia de un único atributo con relación a un umbral (habitualmente la renta). Las segundas se fundan en dar una explicación más amplia en términos de la inclusión de más atributos (Boltvinik, 2007b). Algunas definiciones se muestran en la Tabla 1.

Se podrían citar más definiciones, lo que manifiesta que la conceptualización de la pobreza no ha concluido. Por ello, analizar el fenómeno sigue teniendo validez, en el sentido de que se hace necesario caracterizar e identificar los principales elementos que componen el concepto de pobreza, con el fin de acrecentar el conocimiento del mismo, puesto que una mejor definición representa un paso significativo para comprenderla. Esto implicaría un conocimiento de sus determinantes o causas, lo que colocaría la discusión en el plano de las alternativas de solución para erradicar o aminorar los efectos de la pobreza sobre la existencia de los seres humanos.

\section{Determinantes}

Los determinantes se han contextualizado desde tres planos: individual, local y regional. En el primero, se señala que si la pobreza existe en un individuo, posiblemente cohabitaen todos los habitantes del hogar (Mathus, 2008). En este plano, se destacan tres subdeterminantes: demográfico, económico y social. En el demográfico sobresalen el tamaño del hogar, la tasa de dependencia, y el sexo del jefe de familia. Así, a mayor número de hijos (serían necesarios programas de planificación familiar), sumado a que haya una única persona trabajando en el hogar (debido a la dificultad para insertarse en el mercado laboral), la satisfacción de aspectos esenciales puede verse comprometida. En lo concerniente al subdeterminante económico, la pérdida del ingreso, resultado del desempleo u otras razones, juega un papel relevante a la hora de establecer la capacidad adquisitiva de los individuos de bienes y servicios. Por último, en el terreno de lo social se contemplan aspectos tales como la salud, la nutrición, la educación, entre otros. Nótese que hay interrelación entre los tres subdeterminantes, lo cual significa que la pobreza es un fenómeno multidimensional, que obedece no solo a la ausencia de un atributo, sino de varios. De tal conocimiento, se deriva la importancia de identificar adecuadamente los determinantes de la pobreza. 
Hacia una noción sobre la pobreza

Julián Augusto Casas Herrera - Rodrigo Barichello

Tabla 1. Definiciones del concepto de pobreza

\begin{abstract}
UNIDIMENSIONALES
Para Fields (2001), la pobreza es la incapacidad de un individuo o una familia de disponer de los recursos suficientes para satisfacer sus necesidades básicas.

Para Hagenaars (1986), la pobreza es una situación en la que el bienestar de un hogar, derivado de su disposición de recursos, cae por debajo de un cierto nivel de bienestar mínimo, denominado el umbral de pobreza.
\end{abstract}

La CEPAL (2000) sostiene que "la pobreza significa la carencia de ingresos suficientes con respecto al umbral de ingreso absoluto, o línea de pobreza, que corresponde al costo de una canasta de consumo básico".

Ravallion (1992) arguye que la pobreza existe en una sociedad, cuando una o más personas no tienen un nivel de bienestar económico que les permita tener un mínimo razonable frente a los estándares de la sociedad.

El Banco Mundial (Eumed.net, s.f.). "calcula líneas de pobreza (...) de U\$1 y U\$2 en términos de la Paridad de Poder de Compra (PPC) de 1993, esta mide el poder de compra relativo de las monedas (...) se consideran en pobreza absoluta (...) aquellas personas que viven con menos de U\$1 diario y en pobreza relativa aquellas que viven con menos de U\$2 diarios"12.

\section{MULTIDIMENSIONALES}

Boltvinik, citado por Dieterlen (2007), señala que la pobreza es una situación compleja, expresada en un conjunto de carencias que pueden amenazar la dignidad de quienes las padecen. Sen (1992) señala que la pobreza no debería medirse de acuerdo con el acceso a bienes materiales y sociales, sino que es fundamental que las personas tengan la capacidad de usarlos adecuadamente, para que les permitan proveerse de la libertad para buscar su bienestar. Narayan (2000) señala que la pobreza tiene que ver con "cuatro sistemas de integración social: democrático y jurídico, el mercado de trabajo, el de protección social, y la familia y la comunidad".

Max-Neef et al. (1986) distinguen entre necesidades y satisfactores. Las necesidades son absolutas, ya que son las mismas en todas las culturas y períodos históricos, pero los satisfactores de las necesidades están determinados culturalmente, y por ello, suelen ser diferentes en cada sociedad.

Spicker (2000) registra once posibles formas de identificar la palabra pobreza como necesidad, estándar de vida, insuficiencia de recursos, carencia de seguridad básica, falta de titularidades, privación múltiple, exclusión, desigualdad, clase, dependencia y padecimiento inaceptable.

Fuente: construcción propia a partir de los autores citados.

$\overline{12}$ La línea de indigencia se reajustó en 2008 a \$1.25 al día en PPC de 2005. 
En el plano local se destaca, como el mayor determinante, la infraestructura existente en un determinado territorio. Esto se debe a que la pobreza también tiene que ver con el espacio geográfico en el que habitan las personas (Mathus, 2008), porque este les brinda oportunidades para satisfacer otras necesidades distintas a las alimentarias, tales como: electricidad, agua, escuelas, universidades, hospitales, entre otras. No obstante, hay necesidades que pueden ser relevantes en ciertas sociedades, y en otras no. Por ejemplo, Karelis (2007) señala que en las islas del estado de Chuuk, en Micronesia, no hay coches, teléfonos, clínicas, ni agua corriente y no tienen suministro regular de electricidad para uso doméstico. Sin embargo, los habitantes no se consideran pobres. De ahí que Orshansky (1969) señale que "la pobreza, como la belleza, está en el ojo de quien la percibe". No obstante:

Si el concepto de pobreza ha de tener alguna utilidad, debemos restringirlo al expresar la insatisfacción de aquellas necesidades humanas cuya satisfacción depende de condiciones económicas. De lo contrario, la pobreza se confunde con otras dimensiones del sufrimiento del ser humano. Entonces la capacidad diferenciadora del concepto (su habilidad para distinguir los pobres de los no pobres) se perdería y se volvería inútil como instrumento de política (Boltvinik, 1999, p. 37).

El tercer plano señala que la pobreza suele ser mayor en aquellas áreas geográficas que carecen o presentan insuficiencia en lo que tiene que ver con recursos naturales, lluvias, oportunidades económicas, seguridad, libertad de expresión, igualdad, dotaciones de los hogares, entre otras (Mathus, 2008). También cabe señalar que la actitud de las personas puede ser un determinante que suma a un individuo en la pobreza. Como ejemplo de esto puede indicarse la actitud de mendicidad por parte de algunas personas, que prefieren pedir a buscar trabajo.

Sin embargo, lo anterior no se puede generalizar dado que, también es cierto, en algunas sociedades ${ }^{13}$ hay condiciones estructurales y coyunturales que confinan a los seres humanos a vivir una realidad que repudian, pero que no pueden cambiar porque las variables que lo determinan están fuera de su control, tales como una crisis económica, una catástrofe natural, aspectos institucionales, bloques hegemónicos, entre otras. Por último, como resultado de la pobreza hay otros acontecimientos que se desprenden de la misma. Así, si todos o unos determinantes sumen a algunos individuos $\mathrm{u}$ hogares en situación de pobreza, cabe

$\overline{13}$ Beluche (1996, p. 20) señala que la "sociedad capitalista genera la pobreza por dos vías, distintas pero relacionadas: por un lado, la tendencia permanente a pagar la fuerza de trabajo con un salario igual o ligeramente inferior al costo de su reproducción; por otro lado, la existencia de un permanente "ejército de reserva" desempleado que, a su vez, sirve para presionar la caída de los salarios al mínimo posible, aumentando así la parte de la ganancia empresarial". 
interrogarse por las consecuencias que esta trae a sus vidas.

\section{Consecuencias y tipos}

Narayan (2000) y Narayan y Petesch (2008) resaltan que la pobreza suele manifestarse en: hambre, impotencia, suicidio, falta de voz, aislamiento social, enfermedad, altas tasas de mortalidad, privaciones, corrupción, atropellos a la dignidad, tristeza, humillación, dependencia, mendicidad, vergüenza, analfabetismo, delincuencia, desintegración de los hogares ${ }^{14}$, quebrantamiento de normas sociales, lo que genera desorden $\mathrm{y}$ violencia, tanto a nivel de los hogares, como a nivel regional y nacional.

Igualmente, cabe indicar que las consecuencias de la pobreza se traducen, de manera diferente, en las ciudades y en el campo. Esto lleva a diferenciar entre los tipos de pobreza: urbana y rural ${ }^{15}$. Se distinguen, en principio, por el espacio en el que se desarrollan. También, por las medidas que se requieren aplicar para la erradicación de la pobreza, ya que, por ejemplo, los habitantes del campo se enfrentan a diferentes características respecto a los de la ciudad (Boltvinik \& Hernández, 2000). Por tanto, la ubicación geográfica en la que se encuentren los individuos u hogares, les proporcionará ciertas ventajas y desventajas.
Por ejemplo, las personas del campo se benefician de la agricultura de subsistencia, por lo cual obtienen alimentos más económicos; en cambio, los habitantes de las ciudades tienen más servicios y oportunidades (Banco Mundial, 2005).

Asimismo, cabe señalar que se puede hablar de pobreza estructural y coyuntural en cada uno de los espacios señalados (urbano y rural). La primera se refiere a detectar condiciones permanentes que experimentan los hogares/individuos de una sociedad que les dificultan satisfacer las necesidades básicas a corto plazo; en cambio, la segunda se puede presentar cuando los hogares/individuos, en el corto plazo, caen en situación de pobreza por situaciones como una crisis, pérdida del empleo del jefe del hogar, entre otras. Estos tipos de pobreza se intentan capturar por los distintos métodos de medición de la pobreza, tales como el de necesidades básicas insatisfechas (NBI), LP absoluta, LP relativa, etc.

\section{Medición}

En principio, se podría decir que si aún no se ha definido con precisión qué significa la pobreza, es razonable dudar sobre sus formas de medición. Si es así, se debería preguntar el porqué de estas. Haughton y Khandker (2009) señalan cuatro razones para contestar el interro-

4 Esto sucede cuando las mujeres se convierten en el sostén de la familia, lo que implica una redistribución del poder dentro del hogar.

15 Max Neef et al. (1986) critican el concepto de pobreza tradicional, porque su carácter es totalmente economicista. Estos proponen hablar de pobrezas. De hecho, cualquier necesidad humana fundamental que no es satisfecha, revela una pobreza humana. Se puede hablar, entonces, de pobreza de subsistencia, pobreza de protección, entre otras. 
gante: i) para mantener a los pobres en la agenda; ii) para identificar a los pobres y dirigir las intervenciones apropiadas; iii) para supervisar y evaluar los proyectos y las intervenciones políticas orientadas a los pobres; y iv) para evaluar la eficacia de las instituciones cuyo objetivo es ayudar a los pobres. De hecho, según Ravallion (1998) es fácil ignorar a los pobres si son estadísticamente invisibles. Es decir, si no se les siguiera el rastro a los pobres, posiblemente, el Estado se olvidaría de los mismos. De hecho:

el principal propósito que se persigue con la medición de la pobreza es el de contar con una base para contribuir en la determinación del número de personas que requieren asistencia y seguridad social subsidiada a través de la política pública (Núñez, 2011, p. 6).

En ese sentido, la medición de la pobreza puede optar por dos caminos: calcular los recursos o comparar las condiciones observadas que tiene un hogar/individuo frente a un umbral, que establece el límite de necesidades mínimas que deberían ser satisfechas por este, para dictaminar como pobre a aquel que se halle por debajo del umbral. Sin embargo, ese umbral debe contemplar y abarcar las necesidades mínimas. Empero, aún no hay consenso sobre lo que debería ser considerado como necesidades, ya que se entra en el terreno de establecer lo que debe ser lo suficiente o lo digno, y esto varía de una sociedad a otra, y de una época a otra. Desde allí, es posible ver la dificultad de definir el concepto de pobreza. No obstante, las necesidades se han clasificado como materiales y no materiales. La satisfacción de las primeras depende de condiciones económicas, mientras que las segundas de condiciones no económicas (Boltvinik, 1999).

Hecha esta distinción, la medición de la pobreza requiere de operacionalización, es decir, la forma de cuantificar un determinado concepto de pobreza. Cualquier ejercicio de medición de la pobreza requiere de tres elementos: i) elegir el atributo (monetario o no monetario) de bienestar a evaluar, ii) establecer un umbral que permita clasificar a determinado hogar/individuo como pobre si se sitúa por debajo del mismo, y iii) seleccionar un indicador que dé información sobre la población o un grupo específico (Coudouel, Hentschel \& Wodon, 2002).

Asimismo, la medición de la pobreza implica un ejercicio de identificación y de agregación. La identificación debe contestar la pregunta: ¿quiénes son los pobres? Para responderla se requiere de la definición de un umbral y un(os) atributo(s) que sirven de referentes para diferenciar los pobres de los no pobres. En cambio, la agregación debe resolver el cuestionamiento ¿cómo generar una medida global de la pobrezaa través de un indicador o conjunto de indicadores? (Sen, 1992).

Cabe señalar que los indicadores deben tener unas propiedades deseables que deben satisfacer. Muñoz (1999) señala 
seis: i) monotonicidad (la pobreza aumenta si se da una disminución en el ingreso de una persona pobre); ii) transferencia (la pobreza aumenta si ocurre una transferencia de recursos de un pobre a una persona con más ingreso); iii) foco (la pobreza no se modifica si los ingresos de los no pobres no se han alterado); iv) réplica (si la distribución del ingreso continúa igual, la pobreza no varía cuando la población total cambia); v) bienestar social (el indicador debe dar más peso a las personas con ingresos menores); y vi) descomponibilidad (la medida de pobreza debería separar los componentes de pobreza por grupos, con el fin de que la pobreza total sea resultado de sumar la pobreza por grupos) (Muñoz, González, Arcos, Corredor \& Becerra, 2000).

Existen varios indicadores de la pobreza, pero los más comunes son: incidencia ${ }^{16}$, $\operatorname{profundidad}^{17}$ y $\operatorname{gravedad}^{18}$. No obstante, se presenta dificultad en algunos métodos de medición de la pobreza para estimar un indicador de Sen, que tiene en cuenta en conjunto la incidencia, la profundidad y la gravedad por medio de un índice de Gini (Serrano, 2002). Al respecto se debe indicar que los métodos más utilizados para seguirle el rastro a la pobreza son la LP y las NBI, pero no están exentos de críticas.

Así, las NBI evalúan directamente $y$ efectivamente si los hogares sufren cinco tipos de carencias: i) hogares que ocupan viviendas inadecuadas; ii) hogares que habitan en viviendas sin servicios básicos (agua potable y eliminación de excretas); iii) hogares con hacinamiento crítico (evalúa si hay más de tres personas por cuarto); iv) hogares con inasistencia escolar (incluye a los hogares con al menos un niño de 7 a 11 años que no asiste a la escuela); y v) hogares con alta dependencia económica (evalúa si hay más de tres personas por ocupado, y en los cuales el jefe ha aprobado, como máximo dos años de educación primaria). Para el NBI, un hogar y sus habitantes son pobres si tienen al menos una NBI; pero si tienen más de una NBI se considerarán en situación de miseria.

Las críticas que se le hacen al $\mathrm{NBI}^{19}$ pasan por: i) relacionar pocos bienes y servicios, ii) los niveles exigidos en las variables que las componen son bajos, iii) no diferencia niveles de pobreza ya que todas las personas que tengan una carencia son iguales, iv) solo identifica incidencia y no permite medir ni la brecha

Conocido como el porcentaje de pobres. Divide la población que está por debajo de la LP entre el total de la población.

17 La brecha de la pobreza divide el déficit de renta/consumo global medio con respecto a la LP de toda la población, entre el total de renta/consumo de la población. El indicador señala la cantidad que debe transferirse a los pobres para sacarlos de la pobreza.

18 También denominada brecha de la pobreza cuadrática. El indicador, además de tener en cuenta la distancia que separa a los pobres de la LP, también contempla la desigualdad entre los mismos. Así, le asigna un peso mayor a los hogares/individuos más alejadas de la LP. Este indicador, junto con el de brecha de la pobreza, tiene sus limitaciones a la hora de aplicarse a parámetros no monetarios.

19 Muñoz et al. (2000) señalan que el NBI no es un índice utilitarista, porque se fija en las necesidades en vez de concentrarse en preferencias y gustos. 
ni la gravedad entre pobres; v) concede una misma ponderación a cada uno de sus componentes, vi) solo capta pobres estructurales no coyunturales, vii) en la medida en que el tiempo pasa se observa que algunas variables que conforman el NBI dejan de captar pobreza; viii) puede subestimar la pobreza urbana (Muñoz, 1999; Muñoz et al., 2000).

En cuanto al método de la LP, hay tres modificaciones que suelen utilizarse con alguna frecuencia: LP subjetiva, LP relativa y LP absoluta. La primera realiza una encuesta para medir la percepción de las personas sobre lo que debe ser el presupuesto mínimo necesario y así definir el valor de la LP. Nótese que el umbral entre pobres y no pobres es determinado por la percepción de las personas acerca de su propio bienestar. La LP subjetiva ${ }^{20}$ se puede utilizar en atributos monetarios como no monetarios.

En la $L P$ relativa se utiliza información de la distribución de recursos, y se define la LP como una proporción de alguna noción de estándar de vida, tal como el promedio, la mediana o algún otro cuantil $^{21}$. Nótese que la concepción de la pobreza se evalúa con respecto al estándar de vida de una sociedad específica; así, para este enfoque la pobreza representaría la incapacidad de participar en la vida normal de esa sociedad debido a la carencia de recursos. Igualmente, se debe señalar que este método es más utilizado por los países desarrollados, con excepción de Estados Unidos.

Por último, el método más utilizado en los países en vías de desarrollo es la $L P$ absoluta $^{22}$. Bajo este enfoque, la LP se compone de dos líneas: LP alimentaria (LPA) o línea de indigencia (LI) y LP no alimentaria (LPNA). La LPA incluye una de las necesidades humanas más básicas: la nutrición. Pero no cualquier tipo de nutrición, esta debe ser saludable. Su construcción se clasifica en dos grupos: LPA normativa y LPA seminormativa.

La primera establece una canasta que brinde nutrición saludable y adecuada, pero su principal propósito no es medir la pobreza e incluso pueda que no represente los hábitos de los consumidores. La segunda, la más utilizada en la medición de la pobreza en el mundo, representa el costo de una canasta familiar sujeta a ciertas pautas nutricionales, respetando simultáneamente los hábitos observados del consumidor. La LPA seminormativa se construye a raíz de tres

20 Cabe aclarar que el tema de la pobreza subjetiva es parte de un campo más amplio de análisis sobre las percepciones subjetivas del bienestar, que a veces se menciona con el término economía de la felicidad. Se han diseñado diversos métodos para investigar las percepciones subjetivas, los tres más comunes son: i) pregunta sobre ingreso mínimo -ver Goedhart, Halberstadt, Kapteyn \& Van Praag (1977); ii) pregunta de evaluación del ingreso -ver Grupo de Río (2007); y iii) pregunta sobre la adecuación del consumo -ver Pradhan \& Ravallion (1998).

21 La medida más estable es la mediana, porque evita los valores extremos de la distribución del ingreso. Por eso, la mediana es la más usada para establecer el umbral de pobreza en los países de la Unión Europea.

22 Nótese que los países desarrollados usan el método relativo de la LP, ya que quieren asegurarle a sus habitantes un bienestar medio relativamente alto; mientras que los países subdesarrollados utilizan el método absoluto de la LP, puesto que estos propenden a alcanzar estándares de vida básicos. 
pasos: i) determinación del requisito calórico mínimo necesario ${ }^{23}$ para mantener vivo a un individuo en reposo durante un día; ii) selección de un grupo poblacional de referencia, con el propósito de definir la composición de la canasta básica de alimentos y calcular el coeficiente de Engel (CE) ${ }^{24}$; y iii) especificación del contenido y costo de la canasta de alimentos.

En cuanto a la LPNA, a diferencia de la LPA, no tiene un criterio objetivo sobre un valor de referencia mínimo, debido a la dificultad sobre lo que debe considerarse como necesidades básicas y su nivel de satisfacción. Sin embargo, se procede de esta forma por las dificultades para lograr un consenso general acerca de lo que debería ser considerado. A pesar de ello, la LPNA pretende incluir otro tipo de necesidades tales como vivienda, transporte, vestuario, entre otras. El método que más se utiliza para establecer la LPNA se basa en el CE. Así, la LP surge de dividir la LPA por el $\mathrm{CE}^{25}$. En síntesis, para la LP puede haber dos tipos de pobres, los que se encuentran debajo de la LI o LPA se consideran pobres extremos, mientras que los que están por encima de la LI y por debajo de la LP son pobres ${ }^{26}$.

Finalmente, y a pesar de que a la LP sí es posible estimarle el índice Sen (es decir, la incidencia, la profundidad y la gravedad de la pobreza), también se le hacen siete críticas: i) la estabilidad de la relación del $\mathrm{CE}^{27}$, ii) evalúa la satisfacción potencial de las necesidades básicas y no la satisfacción efectiva, iii) supone que si el hogar/individuo tiene un ingreso superior a la LP, tiene cubiertas todas las NBI; iv) considera que la satisfacción de las necesidades depende solo del ingreso y no de otras dimensiones; por ello, tiende a subestimar la pobreza; v) la estimación de la LP a partir de la LI supone que la estructura de consumo no cambia en el tiempo, vi) la selección de la población de referencia para construir la canasta normativa de alimentos; vii) dadas las dificultades para recoger información certera sobre los ingresos, el enfoque requiere de varios supuestos, lo que debilita sus resultados (Muñoz, 1999; Muñoz et al., 2000).

23 Generalmente, los criterios para evaluar las necesidades de energía y proteínas humanas han provenido de las recomendaciones de la Food and Agriculture Organization (FAO) y la Organización Mundial de la Salud (OMS).

24 Sale de la división entre los gastos alimentarios y los gastos totales observados para la población de referencia Cabe señalar que hay tres variantes para el cálculo del CE. La primera utiliza el CE observado entre los pobres. La segunda usa el CE promedio de la población en su conjunto. La tercera usa el CE de una población objetivo de referencia que debe satisfacer requerimientos nutricionales.

25 Bajo este enfoque, la LP también puede salir de multiplicar la LPA por el inverso del coeficiente de Engel, más conocido como el coeficiente de Orshansky. Esto se debe al trabajo de Mollie Orshansky (1963 y 1965) al establecer las LP de los Estados Unidos.

26 Según el PNUD, en el Informe sobre desarrollo humano (2013, p. 96), de los aproximadamente 6800 millones de habitantes del mundo para 2010, 1200 millones de los habitantes del mundo (17.8\%) viven con menos de US $\$ 1.25$ por día en términos de la paridad del poder adquisitivo y 2800 millones (40 \%) viven con menos de US $\$ 2$.

27 Muñoz (2000) señala que hay cuatro desventajas: i) desvirtúa la esencia de la curva de Engel; ii) no capta el impacto de las variaciones de los precios relativos, por ende, no percibe los efectos de sustitución, lo cual significa que todos los bienes tienen una elasticidad de ingreso igual a uno; iii) la LP es poco sensible a los ciclos de la economía; iv) la LP y la línea de indigencia crecen al mismo ritmo. 
Ante las críticas hechas al NBI y a la LP, Beccaria y Minujin (1987) hicieron un experimento que pretendía comprobar si ambos métodos identificaban a los mismos hogares/individuos como pobres. Con ese propósito, los combinaron y de ahí surgió el método de medición integrada de la pobreza (MIP) ${ }^{28}$, del cual se desprenden cuatro grupos: pobres crónicos, pobres inerciales, pobres recientes e integrados socialmente. El método clasifica como pobres crónicos a aquellos hogares/individuos que tienen, por lo menos, una NBI y que, a la vez, presentan renta/consumo por debajo de la LP. Los pobres inerciales son los que tienen, por lo menos, una NBI pero que reportan renta/consumo por encima de la LP. Los pobres recientes son los que no tienen ni una NBI, pero tienen renta/consumo por debajo de la LP. Los integrados socialmente son los que no tienen ni una NBI y su renta/consumo está por encima de la LP (Muñoz, 1999). Sin embargo, las limitaciones de este método radican en que solo se puede estimar la incidencia, pero no la profundidad ni la gravedad de la pobreza.

No obstante, se debe tener presente que no hay un solo método de medición que esté exento de críticas, debido a las diversas nociones que cada autor tiene sobre la pobreza. En síntesis, Boltvinik (1999) señala que hay dos líneas divisorias en la medición de la pobreza. Por una parte, si se opta por un único atributo de bienestar, se asume una perspectiva unidimensional, pero si se usan varios atributos, se adopta una visión multidimensional. Y por otra, está el carácter o el método directo o indirecto de verificación de la satisfacción de la necesidad por parte del hogar/individuo.

Los métodos directos comparan la condición observada del hogar/individuo con el umbral normativo definido, para verificar la satisfacción efectiva de las necesidades básicas; en cambio, los métodos indirectos calculan los recursos que tiene un hogar/individuo con el fin de compararlos con el umbral seminormativo para dictaminar si este tiene o no la posibilidad de satisfacer sus necesidades básicas (Boltvinik, 1999).

Cabe precisar que en cualquier método se puede optar por tres posiciones: i) no normativa, ii) normativa, y iii) seminormativa. La primera no sigue ninguna norma y se limita a incluir criterios relativos o ad hoc para definir el umbral. La segunda, según Boltvinik (1999), define un(os) umbral(es) "sobre la base de una noción de un nivel mínimo de vida aceptable que luego se compara con la situación observada del hogar". En cambio, la tercera "define un umbral basado en una noción desconectada de un nivel de vida mínimamente aceptable, o no definen un umbral ex ante".

Aun así, hay una tipología de la operacionalización de la medición de la pobreza a raíz de las tres posiciones que se

28 $\quad$ Este método une las principales características del NBI y la LP. Ver las versiones mejoradas en Boltvinik (1999). 
pueden asumir en cada método. En los procedimientos no normativos se encuentran los métodos relativos. En los procedimientos normativos y seminormativos se pueden diferenciar tres métodos: i) multidimensionales directos, ii) unidimensionales indirectos, y iii) multidimensionales combinados.

Así, por ejemplo, el $\mathrm{NBI}^{29}$ adopta una visión multidimensional directa y usa un procedimiento normativo. En cambio, la LP asume una visión unidimensional directa y utiliza un procedimiento seminormativo, porque combina lo normativo en las necesidades alimentarias con lo no normativo en las necesidades no alimentarias. Y el MIP integra los métodos directo e indirecto (multidimensional combinado).

Finalmente, es claro que ningún método de la pobreza escapa a las críticas, ya que depende de la perspectiva de quien lo analice. De modo que es y será difícil que algún método capture todas las dimensiones de la pobreza. Necesariamente se privilegiará uno $\mathrm{u}$ otro aspecto $\mathrm{y}$, en consecuencia, se dejarán otros aspectos esenciales de la naturaleza humana, tales como la justicia, el amor, la incertidumbre, entre otros.

\section{CONCLUSIÓN}

En las anteriores líneas se mostró que la pobreza no puede ser vista como algo normal; por eso es pertinente, en este momento, ampliar el debate sobre esta, y con mayor razón cuando para el 2010, según el Banco mundial, había 1212 millones de pobres extremos y $2800 \mathrm{mi}-$ llones de pobres. Este dato indica que el $40 \%$ de la población mundial sufre de pobreza, lo cual evidencia la relevancia y vigencia del análisis de esta situación, pues lo que está en juego es el sufrimiento de quienes se encuentran sumidos en ella, los cuales, más allá de ser identificados, requieren asistencia a través de políticas públicas orientadas a mejorar su bienestar. Este es el verdadero reto de los gobiernos: aliviar el sufrimiento y mejorar las condiciones y capacidades de los seres humanos que se encuentran en la pobreza.

Por ello, es necesario que los más afectados por la pobreza, sean escuchados y tenidos en cuenta para la elaboración y diseño de políticas económicas, puesto que serían ellos las víctimas en el caso de que las políticas fallen. En este sentido, es conveniente tener una mejor comprensión del fenómeno, y aunque esto solo no resuelve la pobreza en el mundo, por lo menos, con base en esto se podrían plantear políticas conducentes a la reducción de la pobreza. No se puede soslayar la investigación de la pobreza, y la solución debe darse no solamente en los textos, sino en las mismas vidas de quienes la padecen.

$\overline{29} \quad$ Boltvinik (1999) señala que por lo menos hay ocho variantes de este método, entre las más conocidas están el NBI y el índice de pobreza humana. 


\section{REFERENCIAS}

1. Banco Mundial (2005). Examen anual de la eficacia en términos de desarrollo 2004. Washington, D.C.: Infoshop del Banco Mundial.

2. Beluche, O. (1996). Pobreza y neoliberalismo en Panamá. Recuperado de http://bdigital. binal.ac.pa/bdp/pobrezayneoliberalismo.pdf

3. Beccaria, L. \& Minujin, A. (1987). Métodos alternativos para medir la evolución del tamaño de la pobreza. Buenos Aires: INDEC.

4. Boltvinik, J. (1999). Métodos de medición de la pobreza. Conceptos y tipología. Revista latinoamericana de política social, (1), 35-67.

5. Boltvinik, J. \& Hernández, E. (2000). Conceptos de medidas y pobreza. En Pobreza y distribución del ingreso en México (pp. 30-49). México: Siglo XXI.

6. Boltvinik, J. $\left(2007^{\mathrm{a}}\right)$. De la pobreza al florecimiento humano: ¿teoría crítica o utopía? Desacatos, (23), 13-52.

7. Boltvinik, J. (2007b). Elementos para la crítica de la economía política de la pobreza. Desacatos, (23), 53-86.

8. Cepal (2000). Equidad, desarrollo y ciudadanía: una visión global. México, DF.: Cepal.

9. Consiglio, E. (2007). Pobreza, salud y educación. Economía, gestión y desarrollo, (5), 159-175.

10. Coudouel, A., Hentschel, J. \& Wodon, Q. (2002). Medición y análisis de la pobreza. En Banco Mundial. Técnicas básicas y problemas interrelacionados, Volumen 1 (pp. 3-58). Washington, D.C.: Infoshop del Banco Mundial.

11. Cuevas, H. (1993). Introducción a la economía. Bogotá: Universidad Externado de Colombia.

12. Dechile.net (s.f.). Etimología de pobre. Recuperado de http://etimologias.dechile. net/?pobre

13. De Pablo, J.C. (2012). Inequidad y desigualdad no significan lo mismo. Recuperado de http://www.lanacion.com.ar/1464956-inequidad-y-desigualdad-no-significan-lo-mismo

14. De Vos, K. \& Garner, T. (1991). An evaluation of subjective poverty definitions: comparing results from the US and the Netherland. Review of Income and Wealth, (373), 217-285. 
15. Dieterlen, P. (2007). Cuatro enfoques sobre la idea del florecimiento humano. Desacatos, (23), 147-158.

16. Eumed.net. (s.f.). Definición y medición de la pobreza. Recuperado de http://www.eumed. net/tesis/amc/11.htm

17. Feres, J. \& Mancero, X. (2000). Enfoques para la medición. Breve revisión de la literatura. Publicación de las Naciones Unidas, (4), 5-45.

18. Fields, G. (2001). Poverty: concepts and dimensions. In International symposium on poverty: concepts and methodologies. México D. F., México.

19. Goedhart, T., Halberstadt, V., Kapteyn, A. \& Van Praag, B. (1977).The poverty line: concept and measurement. The journal of human resources, (12), 503-520.

20. Grupo de Río (2007). Compendio de mejores prácticas en la medición de la pobreza. Santiago de Chile: Cepal.

21. Hagenaars, M. (1986). The perception of poverty. Amsterdam: North-Holland.

22. Haughton, J. \& Khandker, S. (2009). Handbook on poverty and inequality, Washington, DC: The World Bank.

23. Kapteyn, A., Kooreman, P. \& Willemse, R. (1988). Some methodological issues in the implementation of subjective poverty definitions. The Journal of Human Resources, (23), $222-242$.

24. Karelis, C. (2007). The persistence of poverty. Why the economics of the well-off can't help the poor. New Haven and London: Yale UniversityPress.

25. Mathus, M. (2008, julio). Principales aportaciones teóricas sobre la pobreza. Contribuciones a las Ciencias Sociales. Recuperado de www.eumed.net/rev/cccss.

26. Marx, K. (1967). El Capital, Tomo I. Bogotá: Fondo de Cultura Económica.

27. Max-Neef, M., Elizalde, A. \& Hopenhayn, M. (1986). Desarrollo a escala humana. Una opción para el futuro. Santiago de Chile: Biblioteca CF+S.

28. Muñoz, M., González, J., Arcos, O., Corredor, C. \& Becerra, E. (2000). Dos acercamientos a la pobreza desde las capacidades y desde el ingreso. En CINEP. Inserción precaria, desigualdad y elección social. Bogotá: CINEP. 
29. Muñoz, M. (1999). Los indicadores de pobreza utilizados en Colombia: una crítica. En C. Corredor. Pobreza y desigualdad, reflexiones conceptuales y de medición. Bogotá: UNAL, COLCIENCIAS, CINEP, GTZ.

30. Narayan, D. (2000). La voz de los pobres ¿hay alguien que nos escuche? Barcelona: Mundi-Prensa.

31. Narayan, D. \& Petesch, P. (2008). Salir de la pobreza. Perspectivas interdisciplinarias sobre la movilidad social. Washington, DC: Banco Mundial.

32. Núñez, J. (2011). La nueva línea de pobreza. Tendencia Económica. Informe Mensual de Fedesarrollo, (112), 6-12.

33. Orshansky, M (1963). Children of the poor, Social Security Bulletin, 26 (7), 3-17. pp. 3-13.

34. Orshansky, M. (1965). Counting the poor: another look at the poverty profile, Social Security Bulletin, 28(1), 3-29.

35. Orshansky, M. (1969). How poverty is measured. Monthly Labor Review, 92 (2), 37-41.

36. Pardo, E. (2000). La pobreza en Smith y Ricardo. Revista de Economía Institucional, 2 (2), 111-130.

37. Pradham, M. \& Ravallion, M. (1998). Measuring poverty using qualitative perceptions of welfare. Review of Economics and Statistics, 1-42.

38. Programa de las Naciones Unidas para el Desarrollo (PNUD). (2013). Informe sobre desarrollo humano 2013. El ascenso del Sur: progreso humano en un mundo diverso. Washington DC: PNUD.

39. Punset, E. (2005). El viaje a la felicidad. Las nuevas claves científicas. Barcelona: Destino.

40. Ravallion, M. (1992). Poverty comparisons: a guide to concepts and methods. Washington DC: Harwood Academic Press.

41. Ravallion, M. (1998). Poverty lines in theory and practice. Living Standards Measurement Surveys, (133), 1-35.

42. Rawls, J. (1982). Social unity and primary goods. In A. Sen \& B. Williams. (Eds.). Utilitarianism and Beyond (pp. 159-186). Cambridge: Cambridge University Press. 
43. Real Academia Española. (s.f.). Diccionario de la Real Academia Española. Recuperado de http://lema.rae.es/drae/

44. Rowntree, B. (1901). Poverty: a study of town life. London: MacMillan.

45. Sen, A. (1979). Equality of What? In The Tanner Lecture on Human Values, (pp. 195220). Cambridge: Cambridge University Press.

46. Sen, A. (1992). Sobre conceptos y medidas de pobreza. Revista de comercio exterior, 42 (4), 1-13.

47. Sen, A. (1997). Values, Resources and Development. Cambridge: Harvard University Press.

48. Serrano, M. (2002). El concepto de pobreza, su medición y la relación con los problemas del medio ambiente. Revista Luna Azul, (14), 1-16.

49. Smith, A. (1997). Investigación sobre la naturaleza y causas de la riqueza de las naciones. México: Fondo de Cultura Económica.

50. Spicker, P. (2000). Defining poverty. Document Inter-American Development Bank, $12-$ 36.

51. Townsend, P. (2007). Introducción. En Grupo de Río. Compendio de mejores prácticas en la medición de la pobreza (pp. 13-28). Santiago de Chile: CEPAL.

52. Vargas, M. (2004). Pobreza, mercado y ciudadanía. Revista Iztapalapa, (57), 169-188. 